\title{
Mislukkingvoorspelling vir ondernemings, met inagneming van tydsdimensies ${ }^{1}$
}

\author{
Pierre Olivier \\ Departement Rekeningkunde, Universiteit van Stellenbosch, Stellenbosch 7600, Republiek van Suid-Afrika
}

Ontvang 2 Julie 1991; acnvaar 5 Februarie 1992

\begin{abstract}
Fallure prognosis for companles with due allowance for time dimenslons. In the United States of America it was initially attempted to predict financial failure by means of compiling a failure-prognosis model consisting of a number of weighted ratios. The model developed was a general model which only examined one time dimension of failure, namely, differentiating between solvent and insolvent companies one year prior to financial failure. The model was applied, without any adjustments, in penultimate and prior years, without ascertaining whether the change in time dimension has an influence on the classification results of the model. A similar model was later developed for South African circumstances. This model had the same shortcomings. A possible problem, which was quite likely not taken into account in the compilation of the existing models, was whether a general failure-prognosis model provided the best classification results in all possible circumstances. In this I article endeavour to determine whether or not failureprognosis models, which are compiled for specific circumstances, provide more accurate classification results than a general model. Failure-prognosis models were compiled separately for companies, for periods of one and four years preceding financial failure. The models were interchanged and it was found that results were unreliable when the incorrect model was applied. Models compiled to predict business failure within the first year, for example, did not fare well when applied to earlier years and vice versa.

In die Verenigde State van Amerika is daar aanvanklik probeer om finansiële mislukking met behulp van 'n mislukkingvoorspellingsmodel, bestaande uit ' $n$ aantal verhoudingsgetalle waaraan afsonderlike gewigte loegeken word, te meet. Hierdie model is ' $n$ algemene model wat slegs een dimensie van mislukking ondersoek het, naamlik om in die eerste jaar voor ondergang tussen solvente en insolvente maatskappye te onderskei. Die model is sonder enige aanpassings in die tweede en verdere jare voor mislukking toegepas, sonder om vas te stel of die verandering in die tydsdimensie ' $n$ invloed op die klassifikasieresultate van die model het. Daar is later 'n soortgelyke model vir SuidAfrikaanse omstandighede saamgestel, maar wat onder andere dieselfde tekortkominge bevat het. Mislukkingvoorspellingsmodelle is vir ondernemings vir een en vier jaar voor ondergang saamgestel. Die modelle is onderling wegepas en daar is vasgestel dat resultate aansienlik verswak indien van die verkeerde model gebruik gemaak word. Modelle wat byvoorbeeld saamgestel is om mislukking in die eerste jaar voor ondergang te voorspel, vaar nie so goed in verdere jare voor ondergang, soos modelle wat vir die betrokke jare saamgestel is nie, en omgekeend.
\end{abstract}

\section{Probleemstelling}

Altman (1968) was die eerste persoon wat sukses behaal het deur van 'n model gebruik te maak om mislukking te voorspel. Altman het sy model op grond van verskeie verhoudingsgetalle, met behulp van die statistiese tegniek van diskriminantontleding, saamgestel. Hierdie diskriminantfunksie kan dan in die vorm van 'n mislukkingvoorspellingsmodel gebruik word om te voorspel of onafhanklike maatskappye moontlik gevaar loop om finansieel te misluk.

In Suid-Afrika het De la Rey (1981) die omvattendste studie nog oor mislukkingvoorspellingsmodelle gedoen. De la Rey se model sluit veranderlikes in wat nie sonder meer uit die finansiële state verkrygbaar is nie, wat die model moeilik toepasbaar maak. Die vraag kan egter gestel word of ' $n$ model wat vir Amerikaanse toestande ontwikkel is, sonder meer in Suid-Afrika van toepassing gemaak kan word.

Altman en De la Rey se mislukkingvoorspellingsmodelle is saamgestel uit diskriminantfunksies, wat bepaal is deur 'n diskriminantontleding op 'n steekproef insolvente en solvente maatskappye, een jaar voor ondergang, uit te voer. Deur die samestelling van hierdie modelle te ondersoek, ontstaan die volgende vraag: sal 'n mislukkingvoorspellingsmodel wat vir die eerste jaar voor ondergang saamgestel is, noodwendig die beste klassifikasieresultate in alle ander jare voor ondergang lewer?

Die doel met hierdie ondersoek is om te bepaal of die gebruik van een algemene mislukkingvoorspellingsmodel vir handels- en vervaardigingsondernemings, onder alle om- standighede geregverdig is. Om hierdie doel te bereik, sal verskillende mislukkingvoorspellingsmodelle vir een en vier jaar voor ondergang saamgestel word, en sal hulle onderling toegepas word. Daar sal gepoog word om meer praktiese modelle vir Suid-Afrikaanse omstandighede saam te stel. Hierdie modelle sal ook met Altman se model vergelyk word.

\section{Altman se model}

Altman (1968: 594) se model sien soos volg daanuit:

$$
\begin{aligned}
\mathrm{Z}= & 0.012 \mathrm{X} 1 \%+0.014 \times 2 \%+0.033 \times 3 \%+0.006 \times 4 \% \\
& +0.999 \times 5
\end{aligned}
$$

Waar:

$\mathrm{Z} \quad=$ Telling volgens Altman se model

$\mathrm{X} 1$ = Netto bedryfsbates tot totale bates

$\mathrm{X} 2$ = Onaangewende inkomste tot totale bates

$\mathrm{X} 3$ = Netto inkomste voor rente en belasting tot totale bates

X4 = Markwaarde van ekwiteit tot boekwaarde van skuld

$\mathrm{X} 5$ = Omset tot totale bates

\section{Resultate behaal met Altman se model}

Die klassifikasieresultate wat met Altman se model in die VSA behaal is, word in Tabelle 1 en 2 getoon.

In die eerste jaar voor ondergang is daar uitstekend gevaar, aangesien $95 \%$ van die maatskappye korrek geklassifiseer is. In die tweede jaar voor ondergang het die aantal maatskappye wat korrek geklassifiseer is tot $83 \%$ gedaal. 
Tabel 1 Klassifikasieresultate deur Altman in die eerste jaar voor mislukking behaal

\begin{tabular}{lccc}
\hline $\begin{array}{l}\text { Tipe } \\
\text { maatskappy }\end{array}$ & $\begin{array}{c}\text { Aantal } \\
\text { getoets }\end{array}$ & $\begin{array}{c}\text { Aantal } \\
\text { korrek }\end{array}$ & $\begin{array}{c}\text { Persentasie } \\
\text { korrek }\end{array}$ \\
\hline Insolvent & 33 & 31 & $94 \%$ \\
Solvent & 33 & 32 & $97 \%$ \\
\hline Toual & 66 & 63 & $95 \%$ \\
\hline
\end{tabular}

Tabel 2 Klassifikasieresultate deur Altman in die tweede jaar voor mislukking behaal

\begin{tabular}{lccc}
\hline $\begin{array}{l}\text { Tipe } \\
\text { maatskappy }\end{array}$ & $\begin{array}{c}\text { Aantal } \\
\text { getoets }\end{array}$ & $\begin{array}{c}\text { Aantal } \\
\text { korrek }\end{array}$ & $\begin{array}{c}\text { Persentasie } \\
\text { korrek }\end{array}$ \\
\hline Insolvent & 33 & 23 & $72 \%$ \\
Solvent & 33 & 31 & $94 \%$ \\
\hline Totaal & 66 & 54 & $83 \%$ \\
\hline
\end{tabular}

Uit Tabelle 1 en 2 kan afgelei word dat die grootste probleem met die model is om die insolvente maatskappye korrek te voorspel, veral in die tweede jaar voor ondergang (sien latere bespreking).

Altman se model, wat saamgestel is om finansiele mislukking in die eerste jaar voor ondergang te voorspel, word net so in die tweede jaar voor ondergang toegepas. Hy het nie die moontlikheid ondersoek of die verandering in tydsdimensie ' $n$ invloed op die klassifikasieresultate van sy model sal hê nie.

Deur die modelwaarde vir ' $n$ maatskappy te bereken, kan bepaal word of die maatskappy waarskynlik 'insolvent' sal raak. Waardes groter as die snypunt dui op solvensie, terwyl waardes kleiner as die snypunt op insolvensie dui. Die snypunt is dié punt waar die aantal solvente en insolvente maatskappye wat verkeerd geklassifiseer word, geminimaliseer word. Volgens Altman (1983: 119, 120) moet al die verkeerd geklassifiseerde maatskappye binne die grys area val. Hy het ook bepaal dat die snypunt by die waarde 2.675 is. Die grootste waarde vir 'n insolvente maatskappy was 2.99 en die kleinste waarde vir 'n solvente maatskappy 1.81. Hiervolgens bepaal hy dat die grys area tussen 2.99 en 1.81 val. Altman het nie die waarde by die snypunt van die diskriminantfunksie afgetrek nie, maar sy grys area rondom die oorspronklike snypunt gehou. Dit beïnvloed nie die resultate nie, alhoewel dit makliker vertolkbaar is as die snypunt tussen solvente en insolvente maatskappye nul is.

\section{De la Rey se model}

De la Rey (1981: 341$)$ se model lyk soos volg:

$$
\begin{aligned}
\mathrm{K}= & -0.01662 \mathrm{a}+0.0111 \mathrm{~b}+0.0529 \mathrm{c}+0.076 \mathrm{~d}+0.0174 \mathrm{e} \\
& +0.01071 \mathrm{f}-0.06881 \mathrm{l}
\end{aligned}
$$

Waar:

$\mathrm{a}=$ Totale skuld tor totale bates $\times 100$

b = Inkomste voor rente en belasting tot gemiddelde totale bates $\times 100$ $c=$ Totale bedryfsbates + genoteerde beleggings tot bedryfslaste

d = Inkomste na belasting tot gemiddelde totale bates

e $=$ Kontantvloei na belasting tot gemiddelde totale bates

f = Voorraad tot inflasie-aangesuiwerde totale bates

$0.06881=$ Konstante

Die kriterium vir die voorspelling van finansielle mis. lukking met hierdie model is soos volg: Indien die $\mathrm{K}$-waar. de groter as 0.2 is, voorspel dit finansiěle sukses. Indien die $\mathrm{K}$-waarde kleiner as -0.2 is, voorspel dit finansiěle mislukking. Daar bestaan 'n grys area tussen -0.2 en 0.2 .

Met die toepassing van hierdie model op sy oorspronklike maatskappye het De la Rey 'n gemiddelde voorspellingsakkuraatheid van $96.6 \%, 66.0 \%$ en $75.0 \%$ in onderskeidelik die eerste, tweede en derde jaar voor ondergang behaal.

Ongelukkig maak die keuse van die verhoudingsgetal, voorraad tot inflasie-aangesuiwerde totale bates, die model moeilik toepasbaar.

De la Rey het ook sy model, wat saamgestel is om finansièle mislukking in die eerste jaar voor ondergang te voorspel, net so in die tweede en derde jaar voor ondergang toegepas. Hy het ook nie die moontlikheid ondersoek dat die verandering in die tydsdimensie ' $n$ invloed op die klassifikasieresultate van sy model kan hê nie. Dit verklaar moontlik waarom die klassifikasieresultate wat hy in die tweede en derde jaar voor ondergang behaal het, soveel swakker is as dié in die eerste jaar voor ondergang.

De la Rey het slegs gebruik gemaak van die verhoudingsgetalle wat reeds op die databank van die Buro vir Finansiêle Analise aan die Universiteit van Pretoria beskikbaar was.

\section{Diskriminantanalise}

Volgens Klecka (1975: 435-445) word diskriminantanalise vir twee aspekte gebruik, naamlik diskriminasie en klassifikasie. Die diskriminasie-aspek behels die bepaling van die lineêre kombinasie van veranderlikes om optimaal tussen twee of meer gedefinicerde groepe te diskrimineer. Die klassifikasie-aspek behels die gebruik van die diskrimi. nantfunksie om onbekende waamemings tot een van die groepe te kategoriseer.

Diskriminantanalise is 'n tegniek waarmee daar gepoog word om statisties tussen groepe te onderskei. (Vir die berekening van 'n diskriminantfunksie vir twee groepe, kyk na Bennett \& Bowers [1976: 95-104] .) Volgens Bennett \& Bowers word 'n versameling diskriminantveranderlikes (finansiële verhoudingsgetalle) gekies, wat metings is van die eienskappe waarin die groepe (solvente en insolvente maatskappye) moontlik kan verskil. 'n Diskriminantfunksie word dan bereken wat 'n lineêre kombinasie van die diskriminantveranderlikes is, en wat poog om so beduidend as moontlik tussen die groepe te onderskei. Indien twee grope gebruik word, word met behulp van die diskriminantfunksie probeer om die gemiddeldes van die groepe op 'n enkel dimensie, so ver as moontlik van mekaar te verwyder.

Vir doeleindes van hierdie ondersoek bestaan daar twee groepe, naamlik solvente en insolvente maatskappye. Die insolvente maatskappye het tussen 1970 en 1988 misluk, 
terwyl die finansiěle data van die solvente maatskappye gedurende 'n jaar onttrek is terwyl ekonomiese omstandighede neutraal was. Oor elke maatskappy in die twee groepe is data ingesamel en dit is na verhoudingsgetalle verwerk. Nadat die individuele diskriminasievermoz van 'n groot verskeidenheid verhoudingsgetalle bepaal is, is die diskriminantfunksies saamgestel uit die vyf-en-dertig verhoudingsgetalle wat individueel die beste tussen die groepe gediskrimineer het.

Volgens Klecka (1975: 447-448) word onafhanklike veranderlikes geselekteer vir opname in die diskriminantfunksie afhangende van hulle onderskeie diskriminasievermoëns. Sommige veranderlikes lewer miskien nie 'n betekenisvolle bydrae om die onderskeid tussen die groepe te bepaal nie. As gevolg van die korrelasie tussen veranderlikes, is dit miskien nie nodig om al die veranderlikes in die diskriminantfunksie op te neem nie. Dit is ook moontlik dat ' $n$ veranderlike wat in een stadium ' $n$ hoe diskriminasievermoæ gehad het, die diskriminasievermok kan verloor as gevolg van veranderlikes wat intussen in die diskriminantfunksie opgeneem is, waarmee dit in 'n hos mate korreleer.

Volgens Klecka (1975: 447) begin die proses wanneer die enkele veranderlike wat die beste tussen die groepe diskrimineer, gekies word. Dit word gedoen deur 'n algehele ' $F$ '-waarde vir elke veranderlike te bereken. Volgens Morrison (1969: 157) meet hierdie ' $F$ '-waarde of die twee groepe statisties van mekaar verskil. Morrison (1975: 447) en Lachenbruch $(1975: 25)$ sê verder dat hierdie toets ekwivalent aan Hotelling se $T^{2}$ toets vir die gelykheid van twee vektorgemiddeldes is. Volgens Klecka word die veranderlike met die grootste ' $F$ '-waarde, met die voorbehoud dat dit groter as 'n sekere kritieke waarde is, eerste in die diskriminantfunksie opgeneem. Die diskriminantfunksie kan in hierdie stadium soos volg voorgestel word: $Y=k 1 \times 1$, waar $\mathrm{Y}=$ diskriminantfunksie; $\mathbf{k l}=$ konstante cen en $\times \mathbf{l}=$ veranderlike een.

Die gekose veranderlike word nou met elk van die oorblywende veranderlikes gepaar - een op 'n slag. Die volgende veranderlike, wat saam met die eerste gekose veranderlike die beste diskrimineer, word nou gekies vir opname, met die voorbehoud dat sy additiewe bydrae groter as die kritieke waarde is. Die diskriminantfunksie kan nou soos volg voorgestel word: $Y=k 1 \times 1+k 2 \times 2$, waar $k 2=$ konstante twee en $\times 2=$ veranderlike twee. As 'n verdere veranderlike gekies word vir insluiting, mag dit gebeur dat veranderlikes wat vroeer gekies is, hulle diskriminasievermoè verloor.

Nadat ' $n$ volgende veranderlike gekies is vir opname in die diskriminantfunksie, word daar getoets of die individuele veranderlikes wat reeds in die funksie opgeneem is, se bydrae om die groepsverskille te verklaar, nie kleiner as 'n sekere kritieke waarde is nie. 'n Veranderlike wat vroeer in die diskriminantfunksie opgeneem is se bydrae kan verswak as gevolg van die interkorrelasies tussen die diskriminantveranderlikes. Die gedeelte van die groepsverskille wat deur die betrokke veranderlike verklaar is, word nou deur die kombinasie van ander veranderlikes verklaar. So 'n veranderlike is onnodig en moet verwyder word. 'n Veranderlike wat in een stadium verwyder is, mag wel weer in 'n later stadium opgeneem word as dit in daardie stadium 'n bevredigende bydrae lewer.

Hierdie twee veranderlikes word nou saamgevoeg in 'n lineêre samestelling en gepaar met elk van die corblywende veranderlikes, een op 'n slag. Die volgende veranderlike, wat saam met die eerste twee gekose veranderlikes die beste diskrimineer, word nou gekies vir opname, met die voorbehoud dat sy bydrae groter as die kritieke waarde is. In hierdie stadium kan die diskriminantfunksie soos volg voorgestel word: $Y=k 1 \times 1+k 2 \times 2+k 3 \times 3$, waar $k 3=$ konstante drie en $\times 3=$ veranderlike drie.

Volgens Klecka word die keuse van verdere veranderlikes voortgesit totdat die stadium bereik word waar daar nie meer veranderlikes opgeneem of weggelaat $k a n$ word nie, ondat die corblywende veranderlikes se bydraes kleiner as die kritieke waarde is.

By elke stap word die volgende berekeninge gedoen: Daar word 'n algehele ' $F$ '-waarde bereken om te bepaal of die groepe betekenisvol verskil ten opsigte van die veranderlikes in die diskriminantfunksie. 'n Parsiële ' $F$ '-waarde word vir elke veranderlike, wat nog nie in die diskriminantfunksie opgeneem is nie, bereken met die $00 \mathrm{~g}$ op moontlike insluiting. 'n Parsièle ' $F$ '-waarde word vir elke veranderlike, wat reeds in die diskriminantfunksie opgeneem is, bereken met die oog op moontlike weglating. Hierdie ' $F$ '-waardes is die kritieke waardes vir opname of weglating uit die diskriminantfunksie.

Die finale diskriminantfunksie sal dan soos volg daar uitsien:

$Y=k 1 \times 1+k 2 \times 2+k 3 \times 3+\ldots . . k r \times r$

Volgens Gnanadesikan et al. (1969:61) word stapsgewyse diskriminantontleding op soortgelyke wyse deur die rekenaarpakkette BMDP en SAS uitgevoer. Na oorweging van die pakkette is daar besluit om van BMDP (Dixon, 1983) gebruik te maak.

Mislukkingvoorspellingsmodel vir ondermemings een jaar voor ondergang, met Inagneming van tydsdimensles

Model A wat saamgestel is om mislukking cen jaar voor ondergang te voorspel, sien so daar uit:

$Y=11.18859 \mathrm{X} 1+0.29212 \times 2+0.55119 \times 3-1.195$

$\mathrm{X1}=$ Netto inkomste voor belasting tot totale bates

$\mathrm{X} 2$ = Omset tot totale bates

$\mathrm{X} 3$ = Onaangewende inkomste tot totale bates

$1.195=$ Konstante

Die model is toegepas om die matskappye wat in die daarstelling van die diskriminantfunksie gebruik is, as solvent of insolvent te klassifiseer.

Tabel 3 Klassifikasie met behulp van model A

\begin{tabular}{|c|c|c|c|}
\hline \multirow[t]{2}{*}{ Groep } & \multirow[t]{2}{*}{$\begin{array}{l}\text { Persentasie } \\
\text { korrek }\end{array}$} & \multicolumn{2}{|c|}{$\begin{array}{l}\text { Ameal gevelle in betiok- } \\
\text { ke groep getleneifiseer }\end{array}$} \\
\hline & & Inscivent & Solven \\
\hline Insolvent & $95.8 \%$ & 23 & 1 \\
\hline Solvent & 96.45 & 2 & 53 \\
\hline Tocenl & 96.25 & 25 & 54 \\
\hline
\end{tabular}


Uit Tabel 3 blyk dit dat uitstekende resultate behaal is met die klassifikasie van maatskappye. Slegs een insolvente en twee solvente maatskappye is verkeerd geklassifiseer. Die totale aantal maatskappye wat korrek geklassifiseer is, is $96.2 \%$, waaruit afgelei kan word dat die foutkoers $3.8 \%$ is.

Mislukkingvoorspellingsmodel vir ondernemings vler jaar voor ondergang, met inagneming van tydsdimensles

Model B wat saamgestel is om mislukking vier jaar voor ondergang te voorspel is, lyk soos volg:

$Y=12.08511 \mathrm{X} 1+0.36515 \mathrm{X} 2 \cdot 1.75$

$\mathrm{X} 1=$ Netto inkomste voor belasting tot totale bates

$\mathrm{X} 2=$ Omset tot totale bates

1.75 = Konstante

Die model is toegepas om die maatskappye wat gebruik is in die daarstelling van die diskriminantfunksie, as solvent of insolvent te klassifiseer.

Tabel 4 Klassifikasie met behulp van model $B$

\begin{tabular}{lccc}
\hline Groep & $\begin{array}{c}\text { Persentusie } \\
\text { korrek }\end{array}$ & \multicolumn{2}{c}{$\begin{array}{c}\text { Aantal gevalle in betrok- } \\
\text { ke groep geklassifiseer }\end{array}$} \\
\hline & & Insolvent & Solvent \\
Insolvent & $90.0 \%$ & 18 & 2 \\
Solvent & $90.9 \%$ & 5 & 50 \\
\hline Total & $90.7 \%$ & 23 & 52 \\
\hline
\end{tabular}

Uit Tabel 4 blyk dit dat goeie resultate behaal is met die klassifikasie van maatskappye. Slegs twee insolvente en vyf solvente maatskappye is verkeerd geklassifiseer.

\section{Toepassing van modelle A en B op data vir een jaar voor ondergang}

Modelle A en B is in onderskeidelik die eerste jaar voor ondergang toegepas (Kyk na Tabel 5).

Model A het die beste gevaar deur in totaal $96.20 \%$ van die maatskappye korrek te klassifiseer. Model B het ook goeie klassifikasieresultate gelewer deur $93.67 \%$ van die maatskappye korrek te klassifiseer. Dit is verstaanbaar dat modelle A en B onderling goeie klassifikasieresultate behaal, want beide modelle sluit ooreenstemmende veranderlikes in. Die wegingskoefissiěnte van die ooreenstemmende veranderlikes verskil egter.

Tabel 5 Persentasie maatskappye korrek geklassifiseer, een jaar voor ondergang

\begin{tabular}{lll}
\hline Modelle vir verskillende jare voor ondergang & $\begin{array}{r}\text { Een jaar } \\
\text { Model A }\end{array}$ & $\begin{array}{r}\text { Vier jaar } \\
\text { Model B }\end{array}$ \\
\hline Insolvent korrek geklassifiseer & $95.83 \%$ & $100.00 \%$ \\
Solvent korrek geklassifiseer & $96.36 \%$ & $90.90 \%$ \\
\hline Total & $96.20 \%$ & $93.67 \%$ \\
\hline
\end{tabular}

Model B klassifiseer geen insolvente maatskappye verkeerd nie. Soos vroeur aangetoon, kan die waardes by die snypunte as konstantes van die onderskeie modelle afgetrek word om die snypunte op nul te staan te bring. Nadat die konstante afgetrek is, word insolvente maatskappye verkeerd geklassifiseer indien hulle waardes groter as nul behaal, terwyl die omgekeerde vir solvente maatskappye geld. Hoe groter die waarde van die konstante, hoe minder insolvente maatskappye sal verkeerd geklassifiseer word, maar hoe meer solvente maatskappye sal verkeerd geklassifiseer word.

Die diskriminantveranderlikes wat gebruik is om model A saam te stel, is gebruik om die waardes by die snypunte vir die eerste en die vierde jaar voor ondergang te bepaal. Die waardes by die verskillende snypunte word in Tabel 6 gegee.

In Tabel 6 word aangetoon dat die waardes by die snypunte tussen solvente en insolvente maatskappye toeneem hoe verder daar wegbeweeg word van die datum van ondergang. (Die omgekeerde sou egter plaasgevind het indien die rekenkundige gemiddelde van die veranderlikes in die model normaalweg kleiner vir solvente as vir insolvente ondernemings sou wees.) Dit gebeur omdat die insolvente maatskappye vroeër finansieel gesond was, maar met verloop van tyd verswak het. Vroeèr was die groepsgemiddeldes van verhoudingsgetalle vir die insolvente groep nader of gelyk aan die solvente groep. Die snypunt word dus groter hoe verder daar wegbeweeg word van die datum van ondergang.

As die konstante wat van 'n model afgetrek word, groter is as die waarde van die snypunt tussen die solvente en insolvente maatskappye, veroorsaak dit dat meer insolvente en minder solvente maatskappye korrek geklassifiseer word. As die diskriminantveranderlikes van model B (vier jaar voor ondergang) gebruik word om die snypunt tussen die solvente en insolvente maatskappye een jaar voor ondergang te bepaal, word gevind dat die snypunt by die waarde 1.315 is, terwyl die werklike snypunt vir hierdie model 1.75 is. Deur hierdie groter waarde in die eerste jaar voor ondergang as konstante van model B af te trek, verklaar waarom al die insolvente maatskappye korrek geklassifiseer word. Indien die diskriminantveranderlikes van model B behou word, maar die konstante word na 1.315 aangepas, word $91.66 \%$ van die insolvente en $96.36 \%$ van die solvente maatskappye korrek geklassifiseer (totaal 94.94\%).

\section{Toepassing van Altman se model op data een jaar voor ondergang}

Altman se model is toegepas op die maatskappye een jaar voor ondergang. Volgens Altman (1983: 120) is die snypunt

Tabel 6 Waardes by die snypunte tussen solvente en insolvente maatskappye, soos bepaal met model $\mathbf{A}$

\begin{tabular}{lc}
\hline Jaar voor ondergang & Waarde by die snypunt \\
\hline Een jaar voor ondergang & 1.195 \\
Vier jaar voor ondergang & 1.715 \\
\hline
\end{tabular}


tussen solvente en insolvente maatskappye 2.675. By hierdie punt word daar $83.33 \%$ insolvente en $89.09 \%$ solvente maatskappye korrek geklassifiseer (totaal 87.34\%). Altman (1983: 351) wys daarop dat indien sy model in verskillende lande toegepas word, die gemiddelde tellings verskil. Deur Altman se model te gebruik en die optimum punt te soek waar die minste solvente en insolvente maatskappye verkeerd geklassifiseer word, word die snypunt vir SuidAfrikaanse omstandighede op 2.59 vasgestel. Op hierdie gegewe punt het Altman se aangepaste model $91.66 \%$ insolvente en $89.09 \%$ solvente maatskappye korrek geklassifiseer (totaal $89.87 \%$ ). Indien Altman se model aangepas word, is daar ' $n$ geringe verbetering in die klassifikasie akkuraatheid vir insolvente maatskappye in vergelyking met sy oorspronklike model.

Altman se aangepaste model vaar swakker as model $\mathbf{A}$, wat vir Suid-Afrikaanse omstandighede ontwikkel is, maar die verskil is relatief klein. Daar is aangetoon dat Altman se model 'n groot aantal insolvente maatskappye in die tweede jaar voor ondergang verkeerd geklassifiseer het. Deur die snypunt vir verdcre jare voor ondergang aan te pas, behoort hierdie model heelwat beter klassifikasieresultate te lewer.

\section{Toepassing van die modelle op die data vir vier jaar voor ondergang}

Die modelle is op die data vir vier jaar voor ondergang toegepas en die resultate word in Tabel 7 gegee. Model B het die beste gevaar deur $90.66 \%$ van die maatskappye korrek te klassifiseer.

Tabel 7 Persentasie maatskappye korrek geklassifiseer, vier jaar voor ondergang

\begin{tabular}{lll}
\hline Modelle vir verskillende jare voor ondergang & $\begin{array}{c}\text { Een jaar } \\
\text { Model A }\end{array}$ & $\begin{array}{c}\text { Vier jaar } \\
\text { Model B }\end{array}$ \\
\hline Insolvent korrek geklassifiseer & $70.00 \%$ & $90.00 \%$ \\
Solvent korrek geklassifiseer & $96.36 \%$ & $90.90 \%$ \\
\hline Totaal & $89.33 \%$ & $90.66 \%$ \\
\hline
\end{tabular}

Model A het in die vierde jaar voor ondergang die meeste insolvente maatskappye verkeerd geklassifiseer. Dit kan toegeskryf word aan die feit dat die snypunte tussen solvente en insolvente maatskappye groter word, hoe verder daar wegbeweeg word van die datum van ondergang.

Model B het in die eerste jaar voor ondergang $93.67 \%$ van die maatskappye (insolvent $100 \%$ en solvent $90.90 \%$ ) korrek geklassifiseer, terwyl model A $96.20 \%$ van die maatskappye (insolvent $95.83 \%$ en solvent $96.36 \%$ ) korrek geklassifiseer het. As model A in die vierde jaar voor ondergang toegepas word, word $89.33 \%$ van die maatskappye (insolvent $70.00 \%$ en solvent $96.36 \%$ ) korrek geklassifiseer, terwyl model B $90.66 \%$ van die maatskappye (insolvent $90.00 \%$ en solvent $90.90 \%$ ) korrek geklassifiseer het. Die grootste verskille tussen hierdie modelle is die afsonderlike getal insolvente en solvente maatskappye en nie die totale aantal maatskappye wat korrek geklassifiscer word nie.
Daar is aangetoon dat De la Rey 'n gemiddelde voorspellingsakkuraatheid van $66.0 \%$ en $75.0 \%$ in onderskeidelik die tweede en derde jaar voor ondergang met sy model behaal het. Model A klassifiseer onderskeidelik $91.14 \%$ en 93.67\% van die gevalle in die tweede en derde jaar voor ondergang korrek. Een van die belangrikste aspekte van die gebruik van diskriminantanalise is die klassifikasie van onbekende waarnemings. Uit die resultate kan afgelei word dat model A heelwat beter as De la Rey se model vaar om onbekende waarnemings te klassifiseer.

Hieruit blyk dit dat daar drie faktore in 'n mislukkingvoorspellingsmodel is wat van jaar na jaar kan verskil en sodoende die diskriminasievermoè van 'n betrokke model kan beïnvloed, naamlik:

- die veranderlikes kan verander,

- die wegingskoæffisiënte van die veranderlikes kan verander, en

- die waarde van die snypunt tussen die groepe kan verander.

Altman en De la Rey se modelle is saamgestel uit data een jaar voor ondergang. Dit bring mee dat hierdie modelle nie so goed vaar om potensiële insolvente maatskappye verder as die eerste jaar voor ondergang te identifiseer nie, omdat geen aanpassings vir die verandering in die snypunte en/ of veranderlikes en/of wegingskoeffisiënte van veranderlikes gemaak word nie. Die waarde van mislukkingvoorspellingsmodelle lê juis daarin om potensiêle insolvente maatskappye so vroeg as moontlik te identifiseer, sodat pogings aangewend kan word om die maatskappye se finansiele posisie te verbeter.

Alhoewel die verandering in die snypunt die grootste enkele faktor is vir die swakker klassifikasie in verdere jare voor ondergang, speel die verandering in die veranderlikes, of die verandering in die wegingskoëffisiënte van die veranderlikes ook 'n belangrike rol.

\section{Gebruik van die verskillende modelle}

Soos met Altman en De La Rey se modelle (saamgestel vir een jaar voor ondergang) is dit moontlik om mislukking veel verder as die eerste jaar voor mislukking te bepaal. Daar is byvoorbeeld aangetoon dat model A (een jaar voor ondergang) nog steeds $90.66 \%$ maatskappye vier jaar voor ondergang korrek klassifiseer. Dit is dus onmoontlik om te bepaal in watter stadium van mislukking 'n maatskappy is.

Met die toepassing van modelle $A$ en $B$ is vasgestel dat alle maatskappye wat in die eerste jaar voor ondergang deur model $\mathrm{A}$ as insolvent geklassifiseer word, ook deur model $\mathrm{B}$ as insolvent geklassifiseer word. In die vierde jaar voor ondergang klassifiseer model B egter $25.83 \%$ meer insolvente maatskappye as model A korrek. Al die maatskappye wat deur model $\mathrm{A}$ as insolvent geklassifiseer word, word ook deur model B as insolvent geklassifiseer.

'n Moontlike gebruik vir modelle A en B is om hulle as komplementêr te sien, en om maatskappye met beide modelle te toets. Sodoende sal seker gemaak word dat dit moontlik is om mislukking tot en met die vierde jaar voor mislukking en selfs verder redelik korrek te voorspel. Indien beide modelle op mislukking dui, is die maatskappy waarskynlik op 'n redelik gevorderde stadium van mislukking. Indien model B op mislukking dui, terwyl model A 
nie op mislukking dui nie, is dit 'n aanduiding dat die maatskappy waarskynlik in die toekoms kan misluk, tensy regstellende stappe geneem word.

\section{Gevolgtrekking}

Altman en De la Rey het hulle modelle, wat saamgestel is om finansiêle mislukking in die eerste jaar voor ondergang te voorspel, sonder enige aanpassings in die tweede en/of verdere jare voor ondergang toegepas. Hulle het nie die moontlikheid ondersoek of ' $n$ verandering in die tydsdimensie ' $n$ invloed op die klassifikasieresultate van hulle modelle sal hê nie.

Modelle A en B is onderling op mekaar toegepas en daar is vasgestel dat resultate aansienlik verswak (as daar na die onderskeie insolvente en solvente maatskappye afsonderlik gekyk word) indien die verkeerde model in die verkeerde jaar voor ondergang gebruik word. Mislukkingvoorspellingsmodelle se diskriminasievermoe verswak namate daar verder wegbeweeg word van die datum van mislukking. Dit gebeur omdat die insolvente maatskappye vroeěr finansieel gesond was, hulle was nader of gelyk aan die solvente groep, maar het verder wegbeweeg met die verloop van tyd. Dit veroorsaak dat die waarde van die snypunt tussen solvente en insolvente maatskappye groter word, indien gemeet met veranderlikes waarvan die rekenkundige gemiddelde groter is vir solvente as vir insolvente maatskappye, hoe verder daar wegbeweeg word van die datum van ondergang.

Om doeltreffende klassifikasieresultate in tweede en verdere jare voor ondergang te lewer, moet modelle vir die verandering in die tydsdimensie aangepas word. Deur hierdie aanpassings te maak, verhoog die klassifikasieresultate van mislukkingvoorspellingsmodelle aansienlik teenoor die wat vroeerr met sodanige modelle behaal is.

Daar is aangetoon dat mislukkingvoorspellingsmodelle in drie opsigte oor tyd verander, naamlik: die veranderlikes kan verander, die wegingskoeffisiente van die veranderlikes kan verander en die konstante wat afgetrek word, kan ver. ander.

\section{Nota}

1. Dié artikel vorm deel van 'n doktorale proefskrif in Wysbegeerte aan die Universiteit van Stellenbosch.

\section{Verwysings}

Altman, E.I. 1968. Financial ratios, discriminant analysis and the prediction of corporate bankruptcy. J. Fin., Vol. 23: 589-609.

Altman, E.I. 1983. Corporate financial distress. Kanada: John Wiley \& Sons. Inc., 418p.

Beaver, W. 1966. Financial ratios as predictors of failure. $J$. Accounsing Research, Vol. 4: 71-110.

Bennett, S. \& Bowers, D. 1976. An introduction to multivariale lechniques for social and behavioural sciences. Londen: The Macmillan Press, 156p.

De La Rey, J.H. 1981. Finansiële verhoudingsgetalle en die voorspelling van finansiële mislukkings by nywerheidsondernemings in die Republiek van Suid-Afrika. Ongepubliseerde doktorale proefskrif. Pretoria: Universiteit Pretoria, 286p.

Dixon, W.J. (Chief ed.) 1983. BMDP statistical software. Los Angeles: University of California Press, 726p.

Gnanadesikan, R. 1989. Discriminant analysis and clustering. Statistical Science, Vol. 4, No. 1: 34-69.

Klecka, W.R. 1975. Discriminant analysis. New York: MoCrawHill, 534p.

Lachenbruch, P.A. 1975. Discriminant analysis, New York: Macmillan Publishing Co., 128p.

Morrison, D.G. 1969. On the interpretation of discriminant analysis. J. Marketing Research. Vol. 6: 156-163.

Olivier. P. 1990. Mislukkingvoorspelling vir handels- en vervaardigingsondernemings, veral met die inagneming van verskillende tydsdimensies. Ongepubliseerde doktorale proefskrif in Wysbegeerte. Stellenbosch: Universiteit van Stellenbosch, 546p. 